\title{
Clinical and polysomnographic features of hypertension in obstructive sleep apnea: A single-center cross-sectional study
}

\author{
(D) Aslıhan Gürün Kaya, (D) Banu Gülbay, (D) Turan Acıcan \\ Department of Chest Diseases, Faculty of Medicine, Ankara University; Ankara-Turkey
}

\section{ABSTRACT}

Objective: Obstructive sleep apnea (OSA) is associated with elevated blood pressure (BP) and increases the risk of developing cardiovascular diseases. This study aimed to determine the clinical and polysomnographic features of OSA that are significantly associated with hypertension (HT). Methods: This is a prospective study that enrolled patients diagnosed with OSA in Ankara University Faculty of Medicine from January 2015 to June 2016. The patients were categorized into normotensives $(n=125)$ and hypertensives $(n=141)$. BP was taken at the evening before and the morning after polysomnography (PSG). The polysomnographic findings of normotensive and hypertensive patients were compared, and independent risk factors that are associated with HT were analyzed.

Results: Hypertensive patients exhibited older age and higher Epworth sleepiness scale (ESS), apnea-hypopnea index (AHI), mean apnea duration, arousal index, and oxygen desaturation index (ODI) than normotensive patients. Nocturnal oxygen desaturation (NOD) was more frequent and the percentage of the duration of NOD to total sleep time (TST) was higher in hypertensive than normotensive patients. Multivariate analyses revealed that age (OR: $1.095,95 \% \mathrm{Cl} 1.053$ to $1.139, \mathrm{p}<0.001$ ), ESS (OR: $1.186,95 \% \mathrm{Cl} 1.071$ to $1.313, \mathrm{p}=0.001$ ), mean apnea duration (OR: $1.072,95 \% \mathrm{Cl}$ 1.032 to $1.113, \mathrm{p}=0.002$ ), ODI (OR: $1.062,95 \% \mathrm{Cl} 1.025$ to $1.101, \mathrm{p}=0.001$ ), and NOD (OR: $2.439,95 \% \mathrm{Cl} 1.170$ to 5.086 , $\mathrm{p}=0.017$ ) were independent risk factors for HT in OSA.

Conclusion: This study suggests that age, ESS, parameters of oxygenation, and apnea duration were associated with HT in patients with OSA. Hence, patients with OSA with these findings should be evaluated for HT. (Anatol J Cardiol 2020; 23: 334-41)

Keywords: hypertension, blood pressure, obstructive sleep apnea, polysomnography

\section{Introduction}

Obstructive sleep apnea (OSA) is common medical disorder characterized by repeated episodes of partial or complete obstruction of the upper airways during sleep, associated with blood oxygen desaturation (1). Although it is difficult to determine the exact cause-effect relationship between OSA and systemic hypertension (HT), studies have suggested a strong association between the two (2-4). The potential mechanisms of HT in OSA include intermittent hypoxia leading to increased sympathetic activation, oxidative stress, and endothelial dysfunction. Intermittent apneic episodes provoke hypoxemia, which stimulates the carotid body chemoreceptors and causes reflex sympathetic stimulation. Similarly, arousals can also contribute to this sympathetic activation. Nocturnal catecholamine fluctuations cause resultant notable increase in heart rate and blood pressure (BP) that is most prominent during post-apneic hyperventilation. BP normally decreases ("dips") during sleep by at least $10 \%$. Such falls in nocturnal BP appear to weaken in patients with both HT and OSA $(5,6)$. Although HT and OSA patients manifest common risk factors, such as age, sex, obesity, smoking, and alcohol abuse, OSA has been found to be an important independent risk factor for $\mathrm{HT}(7,8)$.

This study examined the demographic and polysomnographic differences in OSA patients with or without HT and investigated HT determinants.

\section{Methods}

\section{Study group}

Patients diagnosed with OSA (apnea and hypopnea index, $\mathrm{AHI} \geq 5$ times/h) in the sleep disorders laboratory of the Ankara University Faculty of Medicine, Department of Chest Diseases, between January 2015 and June 2016 were enrolled in the study. The study group was divided into two groups, i.e., the hyperten-

Address for correspondence: Dr. Aslıhan Gürün Kaya, Ankara Üniversitesi Tıp Fakültesi, 
sive and normotensive groups. Patients with HT were defined as those with an established diagnosis of HT and ongoing antihypertensive treatment for at least 3 months, based on the electronic national medical record system (MEDULLA). The diagnosis of HT of patients was confirmed from MEDULLA and the hospital medical records system, when systolic BP was higher than $139 \mathrm{~mm}$ $\mathrm{Hg}$ and/or diastolic BP higher than $89 \mathrm{~mm} \mathrm{Hg}$ (9). The following patients were excluded from the study: (1) those younger than 18 years of age; (2) those who underwent split-night polysomnography (PSG); (3) those with inadequate oxygen saturation data on PSG; (4) those previously diagnosed with OSA; (5) those with 2 hours or fewer recording time; and (6) those previously diagnosed with respiratory failure of any etiology.

All the participants signed informed consent forms, and the study design was approved by the Clinical Research Ethics Committee of Ankara University. Self-reported demographic information was provided by all participants. Daytime sleepiness was assessed with Epworth sleepiness scale (ESS) (10). Body mass index (BMI) was calculated as patient's weight in kilograms divided by the square of patient's height in meters.

\section{Polysomnography}

All subjects underwent an overnight PSG using a Grass Comet Plus PSG Polysomnography. Sleep state was assessed by electroencephalography (F4-M1, F3-M2, C3-M2, C4-M1, and 01$\mathrm{M} 2,02-\mathrm{M} 1)$, an electrooculography (E1-M2 and E2-M1), and a chin electromyography using electrode montages.

Arterial oxygen saturation was monitored by pulse oximetry. Episodes of sleep-disordered breathing were assessed using a nasal pressure transducer and thermistor. The parameters, settings, technical specifications, sleep stage scoring, and event scoring were carried out in accordance with the American Academy of Sleep Medicine (AASM) Manual for the Scoring of Sleep and Associated Events. The accepted definition of apnea, hypopnea, desaturation, apnea-hypopnea index (AHI), oxygen desaturation index (ODI), and diagnosis of sleep apnea were based on the AASM guidelines (11-13).

PSG outcome variables included total sleep time (TST), wake after sleep onset (WASO), sleep efficiency (\%), TST percentage in each stage (N1, N2, and N3) and rapid eye movement (REM), arousal index, $\mathrm{AHI}, \mathrm{ODI}$, minimum oxygen saturation, and nocturnal oxygen desaturation. TST was recorded as actual sleep time, excluding periods of wakefulness during the night. Sleep efficiency (\%) was defined as the ratio of TST in a night to the total amount of time spent in bed. WASO was defined as minutes of wakefulness after defined sleep onset. NOD was defined as oxygen saturation $\left(\mathrm{SpO}_{2}\right)<90 \%$ for at least $\geq 30 \%$ of sleep time $(14,15)$. ODI was defined as the number of $>3 \%$ arterial oxygen desaturations per hour of sleep. The arousal index was used to measure sleep and is based on the frequency of EEG arousals per hour. AHI was used to measure the number of apnea and hypopnea events per hour of sleep. Mild, moderate, and severe OSA were defined as AHI of $5-15,16-30$, and $>30$ events/hour, respectively.

\section{Blood pressure}

Patients' BP was measured in two conditions: in the evening before PSG and in the morning after PSG. All BP measurements were performed once on a randomly selected arm of a patient in sitting position.

\section{Statistical analysis}

The data was analyzed using SPSS 22.0 software (SPSS, Inc., Chicago, IL, USA). After making a descriptive statistical analysis of the general characteristics of the study participants, a Kolmogorov-Smirnov test was used to analyze the distribution of variables and a Levene test to assess the equality of variances. Continuous variables with normal distribution were presented as mean \pm standard deviation and as median $\left[25^{\text {th }}-75^{\text {th }}\right.$ percentiles, interquartile range (IOR)] for non-normal variables. An unpaired Student's t-test or a Mann-Whitney U test was used to compare the two groups. Categorical data were expressed as numbers and percentages and compared by chi-square test or Fisher's exact test as appropriate. The correlations between evening and morning BP measurements and demographic features and polysomnographic determinants of individuals were calculated using Pearson correlation coefficient.

The relationships between age, gender, BMI, ESS, and polysomnographic parameters with HT diagnosis were assessed using binary logistic regression analyses. The statistical significance level was expressed as $p<0.05$ for all tests.

\section{Results}

During the study period, a total of 442 patients underwent PSG, and 307 were diagnosed with OSA $179.7 \%$ in the hypertensive group and $69.3 \%$ in the normotensive group, $p=0.016$ ). Out of all these patients, 41 of them were excluded due to missing oxygen saturation data and poor sleep efficiency. The final study sample included a total of 266 patients, diagnosed with OSA (Fig. 1), of whom 141 had HT. The demographic data, ESS scores, and evening/morning BP measurements of the study sample are presented in Table 1.

Upon admission, $88.3 \%$ of the patients had excessive daytime sleepiness, $85.3 \%$ of patients had snoring, $78.2 \%$ of patients had witnessed apneas, $47.4 \%$ of the patients had headache, and $41.4 \%$ of patients had night sweats. Over 102 patients (38.3\%) had at least one comorbid disease other than $\mathrm{HT}$, among which diabetes mellitus $(15.8 \%)$, atherosclerotic heart disease $(9.8 \%)$, and hypothyroidism $(4.9 \%)$ were the most common. The prevalence of a comorbid disease (other than $\mathrm{HT}$ ) was higher in the hypertensive group than in the normotensive group ( $56 \%$ vs. $18.4 \%, p<0.001$ ).

The hypertensive group exhibited more frequent respiratory events and greater oxygen desaturation than the normotensive group. The results of the analyses on polysomnographic and sleep architecture data and nocturnal oxygen saturation levels are summarized in Table 2. 
Table 1. Demographic characteristics and Epworth sleepiness scale scores of the patients

\begin{tabular}{|c|c|c|c|}
\hline & Normotensives $(n=125)$ & Hypertensives ( $n=141$ ) & $\boldsymbol{P}$-value \\
\hline Gender (male) $)^{\S}$ & $79.2 \%(99)$ & $74.5 \%(105)$ & 0.362 \\
\hline Age, year* & $46.80 \pm 10.3$ & $54.87 \pm 9.14$ & $<0.001$ \\
\hline BMI, $\mathrm{kg} / \mathrm{m}^{2 *}$ & $30.47 \pm 4.78$ & $34.46 \pm 6.46$ & $<0.001$ \\
\hline $\mathrm{ESS}^{*}$ & $11.02 \pm 4.45$ & $14.94 \pm 3.72$ & $<0.001$ \\
\hline Diastolic BP & 78 [76-82] & $80[76-86]$ & 0.002 \\
\hline \multicolumn{4}{|c|}{ Morning BP mm Hg," } \\
\hline Systolic BP & 120 [114-128] & 128 [120-132] & $<0.001$ \\
\hline Diastolic BP & $74[70-76]$ & $78[70-80]$ & $<0.001$ \\
\hline
\end{tabular}

Table 2. Polysomnographic parameters of normotensive and hypertensive patients

\begin{tabular}{|c|c|c|c|}
\hline & Normotensives ( $n=125)$ & Hypertensives ( $n=141$ ) & $\boldsymbol{P}$-value \\
\hline TST $(\min )^{*}$ & $300.50 \pm 61.63$ & $289.50 \pm 67.08$ & 0.019 \\
\hline Sleep efficiency $(\%)^{*}$ & $86.7[77.9-91.8]$ & $82.2[73.15-89.4]$ & 0.001 \\
\hline WASO $(\min )^{*}$ & 38 [21-62] & $54.6[31.5-83.0]$ & 0.001 \\
\hline REM latency $(\min )^{\#}$ & 143 [87.5-187] & $108[55-203]$ & 0.079 \\
\hline Arousal index & $15.2[10.6-19.25]$ & $17.3[11.0-24.7]$ & 0.015 \\
\hline $\mathrm{N} 1(\%)^{\#}$ & $10.4[3.9-17.9]$ & $11.7[4.05-22.35]$ & 0.104 \\
\hline $\mathrm{N} 2(\%)^{*}$ & $62.7[51.7-72.6]$ & $63.3[54.8-70.1]$ & 0.600 \\
\hline N3 $(\%)^{\#}$ & $15.1[3.45-25.75]$ & $13.1[4.5-21.6]$ & 0.520 \\
\hline $\operatorname{REM}(\%)^{*}$ & $10.1[5.3-14.1]$ & $7.6[2.3-13.8]$ & 0.019 \\
\hline $\mathrm{AHI}^{*}$ & $15.8[10.2-34.55]$ & $36.6[18.2-63.5]$ & $<0.001$ \\
\hline Mean apnea duration $(\mathrm{sec})^{\#}$ & $14.1[11.7-20.4]$ & $17.8[13.5-22]$ & 0.008 \\
\hline Mean hypopnea duration (sec)\# & 16.5 [14.7-19.9] & 16.4 [14.5-19.2] & 0.523 \\
\hline Minimum oxygen saturation $(\%)^{\#}$ & 84 [77-87] & $76[71-83.5]$ & $<0.001$ \\
\hline Oxygen desaturation index & $4.7[0.85-11.6]$ & $15.7[8.65-29.8]$ & $<0.001$ \\
\hline NOD & $26(20.8 \%)$ & $89(63.1 \%)$ & $<0.001$ \\
\hline
\end{tabular}

After categorizing the patients into the prespecified groups according to $\mathrm{AHI}$, the hypertensive group were found to experience a higher percentage of moderate $(27.7 \%$ vs. $20.8 \%, p<0.001)$ and severe $(60.3 \%$ vs. $32 \%, \mathrm{p}<0.001)$ OSA compared to the normotensive group (Fig. 2). To reduce the possible effects of disease severity, a subgroup analysis was made on patients with severe OSA, which produced findings similar to the entire study group. The detailed results of this analysis are presented in Table 3.

Among the patients reported with NOD, the percentage of TST associated with oxygen saturation of $<90 \%($ T $90 \%)$ was sig- nificantly higher in the hypertensive group than in the normotensive group $(p<0.001)$. Furthermore, this significant difference persisted in the subgroup analysis of patients with severe OSA (Fig. 3).

Mean apnea duration, ODI, and NOD were positively correlated with increased BP both in the morning and evening. The results of the correlation analysis of the determinants of evening and morning BP measurements are presented in Table 4.

In order to determine the effect of clinical and polysomnographic parameters on HT risk in patients with OSA, a binary lo- 


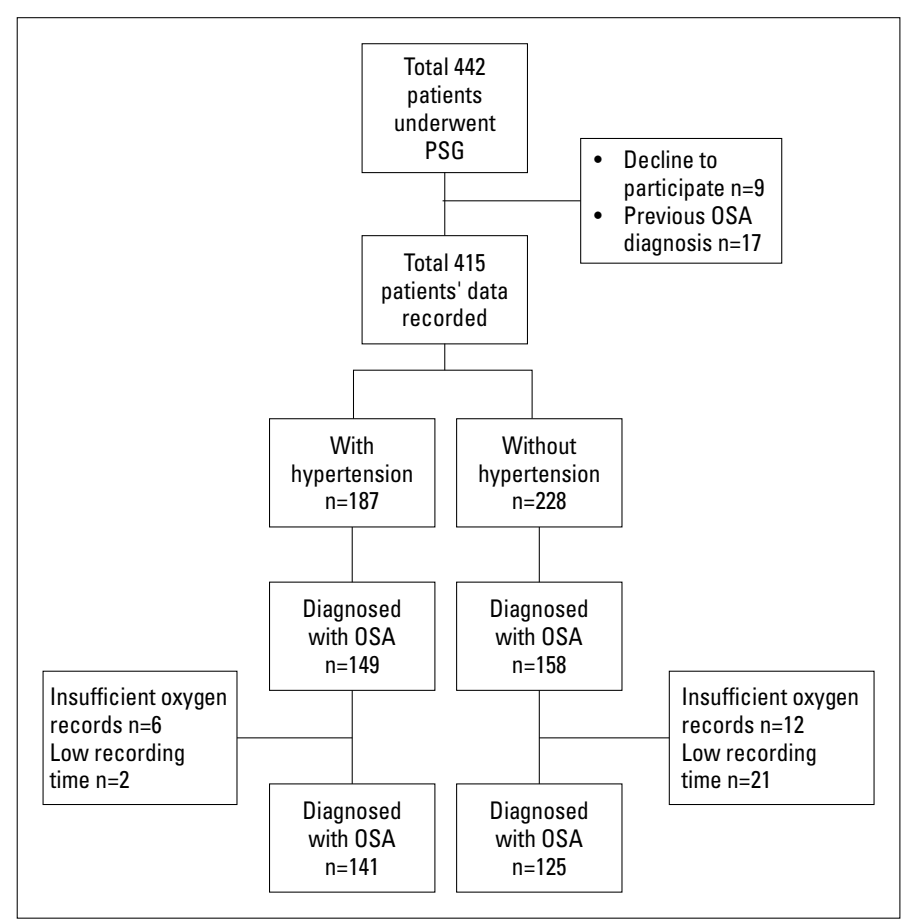

Figure 1. Study flow chart diagram

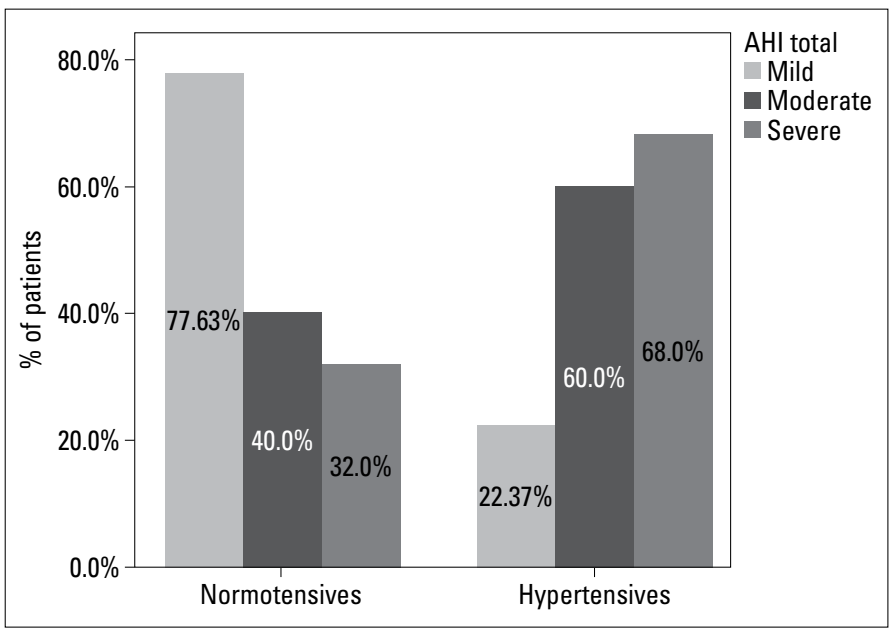

Figure 2. Distribution of OSA severity among patients

gistic regression analysis was employed, revealing that age, ESS, mean apnea duration, ODI, and NOD are significantly associated with HT (Table 5).

\section{Discussion}

In this cross-sectional study, the clinical and polysomnographic characteristics of OSA patients, which are significantly associated with $\mathrm{HT}$, were evaluated. The presence of comorbidities was higher in the hypertensive group than in the normotensive group. Moderate and severe OSA were more frequent in the hypertensive group than in the normotensive group. The study also showed that age, mean apnea duration, increased ODI, and

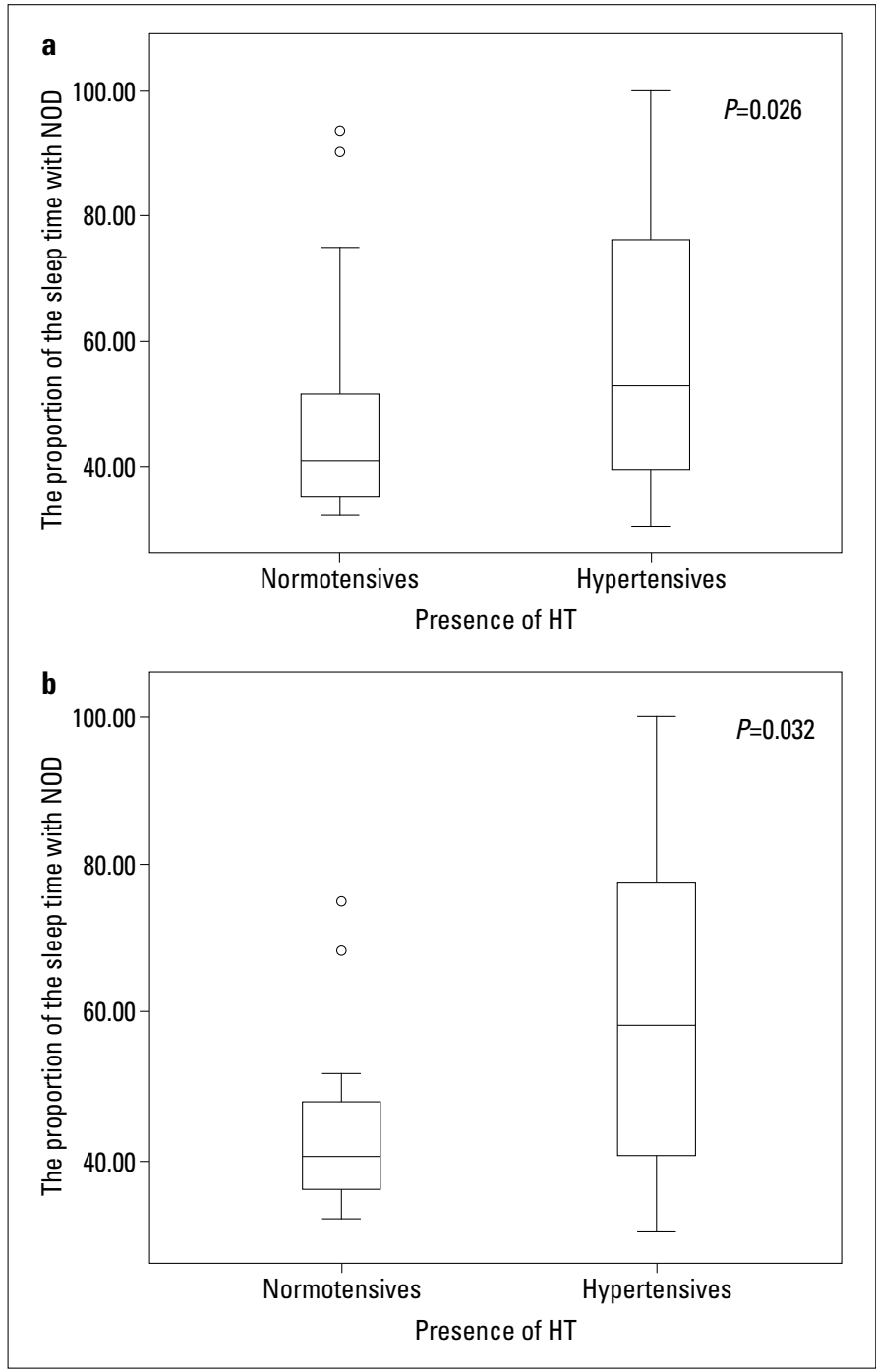

Figure 3. (a) The percentage of TST with oxygen saturation of $<90 \%$. (b) The percentage of TST with oxygen saturation of $<90 \%$ in patients with severe OSA

the presence of NOD were independent risk factors for HT in OSA.

The available data relating to the interaction between OSA and $\mathrm{HT}$ is continuously increasing. According to previous studies, the prevalence of $\mathrm{HT}$ in OSA patients has been estimated at between $30 \%$ and $70 \%(3,4)$. The relationship between OSA and $\mathrm{HT}$ is bidirectional. OSA is common in hypertensive cases, especially in patients with resistant HT (16). In this study, among the patients who underwent PSG, the hypertensive group had higher OSA prevalence than the normotensive group.

Multiple potential mechanisms play a role in the relationship between HT and OSA, among which intermittent hypoxia is of particular note. Hypoxia stimulates the sympathetic nervous system by increasing catecholamine secretion, decreasing baroreflex, and enhancing chemoreceptor sensitivity and contributes to a rise in BP. The activation of reactive oxygen species induced by intermittent hypoxia contributes to endothelial dysfunction, 
Table 3. Polysomnographic parameters of normotensive and hypertensive patients in the severe OSA subgroup

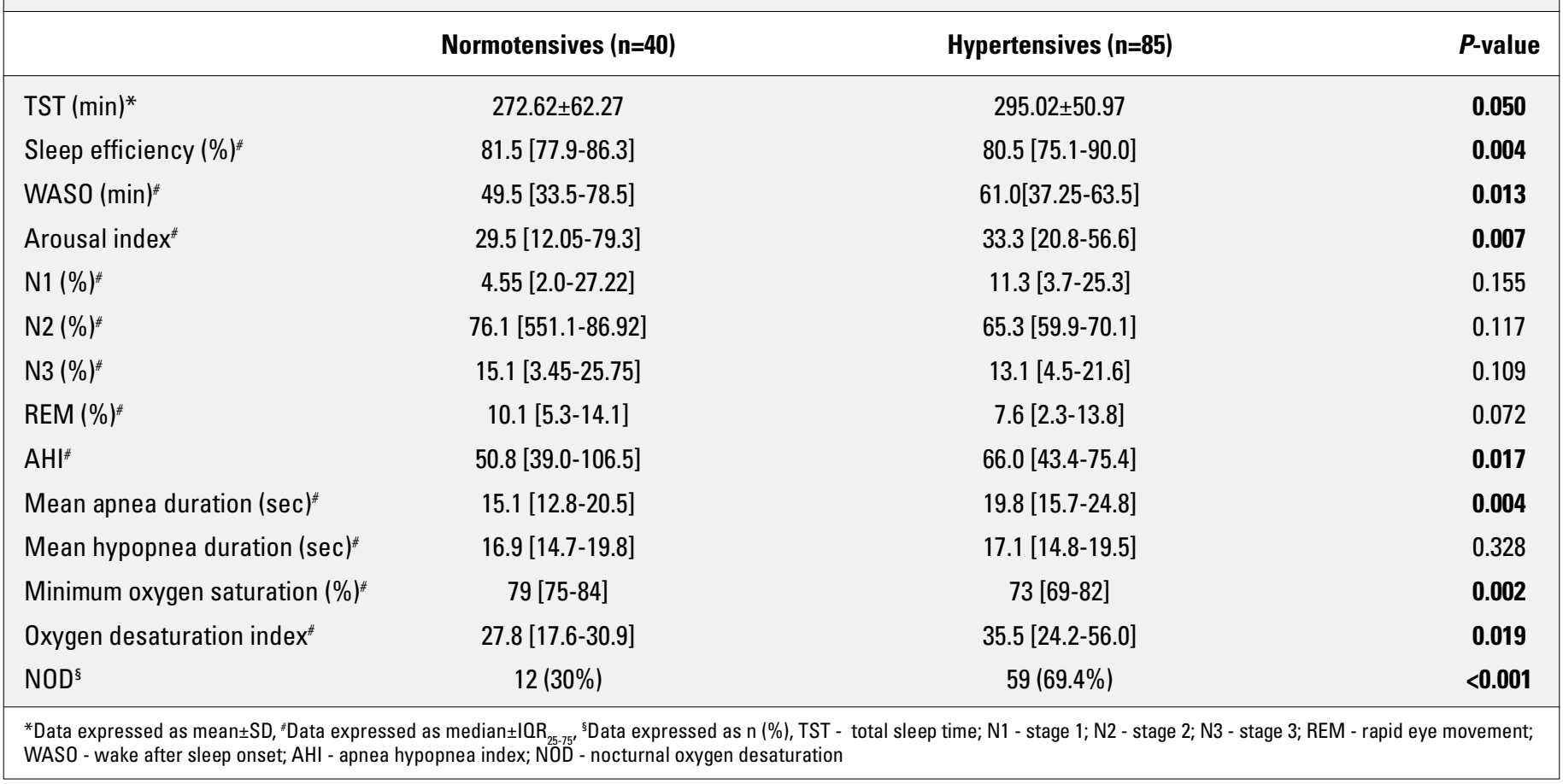

Table 4. Correlation analysis of determinants of evening and morning blood pressure

\begin{tabular}{|c|c|c|c|c|c|c|c|c|}
\hline & \multicolumn{2}{|c|}{ Evening SBP } & \multicolumn{2}{|c|}{ Evening DBP } & \multicolumn{2}{|c|}{ Morning SBP } & \multicolumn{2}{|c|}{ Morning DBP } \\
\hline & $\mathbf{r}$ & $\boldsymbol{P}$-value & $\mathbf{r}$ & $\boldsymbol{P}$-value & $\mathbf{r}$ & $\boldsymbol{P}$-value & $\mathbf{r}$ & $\boldsymbol{P}$-value \\
\hline Age & 0.075 & 0.225 & 0.104 & 0.092 & 0.070 & 0.254 & 0.168 & 0.006 \\
\hline Male, $\mathrm{n}(\%)$ & -0.007 & 0.907 & 0.009 & 0.890 & -0.019 & 0.761 & -0.29 & 0.638 \\
\hline BMI & 0.032 & 0.602 & 0.025 & 0.688 & 0.123 & 0.044 & 0.218 & $<0.001$ \\
\hline ESS & 0.012 & 0.851 & 0.075 & 0.224 & 0.057 & 0.358 & 0.198 & 0.001 \\
\hline Sleep efficiency & 0.057 & 0.358 & -0.032 & 0.607 & -0.018 & 0.770 & -0.082 & 0.182 \\
\hline $\mathrm{AHI}$ & 0.110 & 0.074 & 0.172 & 0.005 & 0.183 & 0.003 & 0.251 & $<0.001$ \\
\hline WASO & -0.074 & 0.229 & 0.007 & 0.916 & -0.011 & 0.852 & 0.077 & 0.212 \\
\hline Arousal index & 0.056 & 0.362 & 0.124 & 0.044 & 0.110 & 0.073 & 0.223 & $<0.001$ \\
\hline Mean apnea duration & 0.172 & 0.005 & 0.226 & $<0.001$ & 0.125 & 0.042 & 0.174 & 0.005 \\
\hline ODI & 0.164 & 0.007 & 0.204 & 0.001 & 0.232 & $<0.001$ & 0.344 & $<0.001$ \\
\hline NOD & 0.318 & $<0.001$ & 0.326 & $<0.001$ & 0.476 & $<0.001$ & 0.686 & $<0.001$ \\
\hline T90\% & 0.184 & 0.049 & 0.148 & 0.115 & 0.178 & 0.056 & 0.167 & 0.074 \\
\hline
\end{tabular}

inflammation, and arterial remodeling, thus leading to vasoconstriction (17-19). This study revealed that ODI, the presence of NOD, and T90\%, being nocturnal hypoxemia-related factors, were significantly higher in the hypertensive group than in the normotensive group. Furthermore, ODI and NOD were correlated with increased evening and morning BP. A multivariate logistic regression analysis indicated that $\mathrm{ODI}(\mathrm{OR}, 1.062 ; 95 \% \mathrm{Cl}, 1.025$ to $1.101 ; \mathrm{p}=0.001$ ), NOD (OR, $2.439 ; 95 \% \mathrm{Cl}, 1.170$ to $5.086 ; \mathrm{p}=0.017$ ) was significantly associated with HT. Similar to our results, Natsios et al. (7) reported a significantly higher ODI in hypertensive patients than in normotensive patients and also found that increased ODI is a significant determinant of $H T$ in patients with OSA. In addition, Min et al. (20) noted a higher ODI in OSA patients with resistant $\mathrm{HT}$ than with controlled HT. 
Table 5. Binary logistic regression analysis between hypertension and other variables

\begin{tabular}{|c|c|c|c|c|}
\hline & B & $\boldsymbol{P}$-value & OR & 95\% Cl for OR \\
\hline Male gender & -0.067 & 0.871 & 0.935 & $0.419-2.089$ \\
\hline Age & 0.091 & $<0.001$ & 1.095 & $1.053-1.139$ \\
\hline BMI & 0.046 & 0.249 & 1.047 & $0.970-1.131$ \\
\hline ESS & 0.170 & 0.001 & 1.186 & $1.071-1.313$ \\
\hline Sleep efficiency & -0.002 & 0.931 & 0.998 & $0.945-1.053$ \\
\hline WASO & 0.011 & 0.180 & 1.011 & 0.995-1.027 \\
\hline Arousal index & 0.018 & 0.234 & 1.018 & $0.989-1.050$ \\
\hline $\mathrm{AHI}$ & 0.027 & 0.054 & 0.973 & $0.947-1.000$ \\
\hline Mean apnea duration (sec) & 0.069 & 0.002 & 1.072 & $1.032-1.113$ \\
\hline Oxygen desaturation index & 0.061 & 0.001 & 1.062 & $1.025-1.101$ \\
\hline NOD & 0.892 & 0.017 & 2.439 & $1.170-5.086$ \\
\hline T90\% & 0.029 & 0.096 & 1.029 & $0.995-1.065$ \\
\hline
\end{tabular}

Arousals are associated with transient increases in BP, heart rate, cerebral blood flow, and ventilation and hence are considered to be a potential cause of HT in patients with OSA. Studies have identified the frequency of arousals to be correlated with $\mathrm{BP}$, although this has not yet been fully explained $(21,22)$. In this study, the hypertensive group scored higher in the arousal index than the normotensive group, both in the whole study group and severe OSA subgroup. The arousal index has further been associated with diastolic evening BP and diastolic and systolic morning BP. Similarly, Natsios et al. (7) and Garcia et al. (22) identified the arousal index to be significantly higher in hypertensive patients than in normotensive patients. Aside from these results, Garcia et al. (22) found that while BP increased during arousal, the magnitude of the increase in systolic BP was significantly higher in the hypertensive group than in the normotensive group.

There have been numerous investigations on the relationship between HT and respiratory events. The Wisconsin Sleep Cohort Study identified a relationship between OSA severity and the incidence of $H T$, but found this association to be unrelated to such confounding risk factors such as age, sex, BMI, and initial BP (23). Likewise, the Vitoria Sleep Cohort Study identified a positive correlation between HT and OSA severity, although this relationship was diminished after adjustment for age, sex, $\mathrm{BMI}$, and smoking history (24). In this study, AHI was higher in hypertensive patients than in the normotensive group, although the association became insignificant after multivariate analysis. Furthermore, the results of this study revealed longer mean apnea duration in the hypertensive group than in the normotensive group. A logistic regression analysis identified a significant correlation between mean apnea duration and HT (OR, 1.072; $95 \% \mathrm{Cl}, 1.032$ to $1.113 ; \mathrm{p}=0.002$ ). The mean apnea duration was further found to be correlated with both evening and morning BP.
Wu et al. (25) found that longer apnea duration is associated with moderate to severe $\mathrm{HT}$ (OR: $1.072,95 \% \mathrm{Cl} 1.019$ to $1.128, \mathrm{p}=0.007$ ). In contrast, a cross-sectional study found no significant differences in apnea duration in the controlled HT and resistant HT groups (20). These findings suggested that some hypertensive patients exhibited mild AHI values, but longer apnea duration. The total duration of apnea events can probably lead to desaturation and may be correlated with sympathetic activation and $\mathrm{HT}$. Although the severity of OSA is measured using AHI, oxygen desaturation and the mean apnea duration parameters appear to be more effective in identifying cardiovascular complications.

Male gender, increased age, and a high $\mathrm{BMI}$ are common risk factors for both OSA and $\mathrm{HT}(3,7)$. This study found that age and BMI were higher in patients with HT than those without HT. Moreover, multiple regression analysis revealed age to be associated with $\mathrm{HT}$, while gender and BMI were not. Natsios et al. (7) identified age and BMI as predictors of $\mathrm{HT}$. In a subgroup analysis made for Sleep Heart Health Study, OSA patients younger than 60 years of age were more likely to develop HT (26). In another study, Wang et al. (27) found that hypertensive group patients were older than the normotensive group, while there was no significant difference in terms of gender. The Vitoria Sleep Cohort Study demonstrated that the association between OSA and HT occurred only in those of the male gender (28). In contrast to our results, BMI was found in another study as a predictor of $\mathrm{HT}$ in OSA (29). Despite numerous data, the effect of gender, age, and $\mathrm{BMI}$ on HT in OSA is not clear. However, the association may depend on multiple factors. Larger studies, especially involving more women, are needed to identify the effect of HT in OSA among different gender and age groups.

ESS is widely used to measure the subjective level of daytime sleepiness and is associated with sympathetic hyperactiv- 
ity and cardiovascular disease in patients with OSA $(30,31)$. ESS may also identify a risk for HT among healthy adults (32). Feng et al. (31) observed that ESS may be an indicator of BP profile in OSA patients. In contrast, Tam et al. (33) found that ESS was lower in hypertensive patients than in the normotensive group. In this study, ESS was significantly higher in the hypertensive group than in the normotensive group and was also correlated with morning systolic BP. Furthermore, logistic regression analysis showed ESS to be associated with HT. It would seem that ESS may be associated with $\mathrm{HT}$ in patients with OSA, although the nature of the relationship is not certain.

Sleep efficiency was found to be significantly lower in the hypertensive group than the normotensive group in this study, but became insignificant with a logistic regression analysis. Similar to sleep efficiency, WASO was found to be insignificant in a multivariate analysis, but significantly higher in the hypertensive group than in the normotensive group. Both sleep efficiency and WASO are associated with poor sleep quality, while short sleep duration and poor sleep quality are associated with cardiovascular pathologies (34).

\section{Study limitations}

There are some limitations to our study. First, among the patients with HT, some BP measurements were less than 140/90 $\mathrm{mm} \mathrm{Hg}$, but we were unable to identify whether this was controlled by medication. Morning and evening BP measurements of some individuals might be unreliable because of non-dipping pattern or white-coat HT. Ambulatory BP monitoring or home BP measurements should be used for antihypertensive treatment goals (35). Additionally, evening and morning BP of patients was measured from a randomly selected arm and hence may produce incorrect measurements, given the potential difference in BP between the left and right arm. Ideally, BP should be measured from both arms. Another limitation is that we did not determine the possible underlying causes of secondary $\mathrm{HT}$, which also may affect the results of the study.

\section{Conclusion}

A significant relationship exists between OSA and HT. As both diseases have common risk factors, the prevalence of HT in patients with OSA is high. ODI, NOD, and apnea duration were the most accurate predictive factors for the development of $\mathrm{HT}$. Patients experiencing nocturnal desaturations should be evaluated for $\mathrm{HT}$ and other cardiovascular complications.

\section{Conflict of interest: None declared.}

Peer-review: Externally peer-reviewed.

Authorship contributions: Concept - A.G.K., B.G., T.A.; Design - A.G.K., B.G., T.A.; Supervision - A.G.K., B.G., T.A.; Fundings - A.G.K., B.G., T.A.; Materials - A.G.K., B.G., T.A.; Data collection and/or process- ing - A.G.K., B.G., T.A.; Analysis and/or interpretation - A.G.K., B.G., T.A.; Literature search - A.G.K., B.G., T.A.; Writing - A.G.K., B.G., T.A.; Critical review - A.G.K., B.G., T.A.

\section{References}

1. Oaseem A, Dallas P, Owens DK, Starkey M, Holty JE, Shekelle P; Clinical Guidelines Committee of the American College of Physicians. Diagnosis of obstructive sleep apnea in adults: a clinical practice guideline from theAmerican College of Physicians. Ann Intern Med 2014; 161: 210-20. [CrossRef]

2. Daugherty SL, Powers JD, Magid DJ, Tavel HM, Masoudi FA, Margolis $\mathrm{KL}$, et al. Incidence and prognosis of resistant hypertension in hypertensive patients. Circulation 2012; 125: 1635-42. [CrossRef]

3. Torres G, Sánchez-de-la-Torre M, Barbé F. Relationship Between OSA and Hypertension. Chest 2015; 148: 824-32. [CrossRef]

4. Ahmad M, Makati D, Akbar S. Review of and Updates on Hypertension in Obstructive Sleep Apnea. Int J Hypertens 2017; 2017: 1848375. [CrossRef]

5. Wolf J, Hering D, Narkiewicz K. Non-dipping pattern of hypertension and obstructive sleep apnea syndrome. Hypertens Res 2010; 33: 867-71. [CrossRef]

6. Legramante JM, Galante A. Sleep and hypertension: a challenge for the autonomic regulation of the cardiovascular system. Circulation 2005; 112: 786-8. [CrossRef]

7. Natsios G, Pastaka C, Vavougios G, Zarogiannis SG, Tsolaki V, Dimoulis A, et al. Age, Body Mass Index, and Daytime and Nocturnal Hypoxia as Predictors of Hypertension in Patients With Obstructive Sleep Apnea. J Clin Hypertens (Greenwich) 2016; 18: 146-52. [CrossRef]

8. Turgut Celen Y, Peker Y. Cardiovascular consequences of sleep apnea: II-Cardiovascular mechanisms. Anatol J Cardiol 2010; 10: 168-75. [CrossRef]

9. Mancia G, Fagard R, Narkiewicz K, Redón J, Zanchetti A, Böhm M, et al.; Task Force Members. 2013 ESH/ESC Guidelines for themanagement of arterial hypertension The Task Force for the management ofarterial hypertension of the European Society ofHypertension (ESH) and of the European Society of Cardiology (ESC). J Hypertens 2013; 31: 1281-357. [CrossRef]

10. Johns MW. Reliability and factor analysis of the Epworth Sleepiness Scale. Sleep 1992; 15: 376-81. [CrossRef]

11. Berry RB, Budhiraja R, Gottlieb DJ, Gozal D, Iber C, Kapur VK, et al.; American Academy of Sleep Medicine. Rules for scoring respiratory events in sleep: update of the 2007 AASM Manual for the Scoring of Sleep and Associated Events. Deliberations of the Sleep Apnea Definitions Task Force of the American Academy of Sleep Medicine. J Clin Sleep Med 2012; 8: 597-619. [CrossRef]

12. Iber C, Ancoli-Israel S, Chesson AL Jr., Quan SF; for the American Academy of Sleep Medicine. The AASM manual for the scoring of sleep and associated events: rules, terminology and technical specifications. 1st ed. Westchester, IL: American Academy of Sleep Medicine, 2007.

13. The AASM Manual for the Scoring of Sleep and Associated Events Summary of Updates in Version 2.1. July 1, 2014. URL; https:// j2vjt3dnbra3ps7II1 clb4q2-wpengine.netdna-ssl.com/wp-content/ uploads/2017/11/Summary-of-Updates-in-v2.1-FINAL.pdf.

14. Ortega Ruiz F, Díaz Lobato S, Galdiz Iturri JB, García Rio F, Güell Rous R, Morante Velez F, et al.; SEPAR. Continuous home oxygen therapy. Arch Bronconeumol 2014; 50: 185-200. [CrossRef] 
15. Lacasse $Y$, Sériès F, Martin S, Maltais F. Nocturnal oxygen therapy in patients with chronic obstructive pulmonary disease: A survey of Canadian respirologists. Can Respir J 2007; 14: 343-8. [CrossRef]

16. Jhamb M, Unruh M. Bidirectional relationship of hypertension with obstructive sleep apnea. Curr Opin Pulm Med 2014; 20: 558-64.

17. Dewan NA, Nieto FJ, Somers VK. Intermittent Hypoxemia and OSA Implications for Comorbidities. Chest 2015; 147: 266-74. [CrossRef]

18. Sforza E, Roche F. Chronic intermittent hypoxia and obstructive sleep apnea: an experimental and clinical approach. Hypoxia (Auckl) 2016; 4: 99-108. [CrossRef]

19. Bosc LV, Resta T, Walker B, Kanagy NL. Mechanisms of intermittent hypoxia induced hypertension. J Cell Mol Med 2010; 14: 3-17.

20. Min HJ, Cho YJ, Kim CH, Kim DH, Kim HY, Choi JI, et al. Clinical Features of Obstructive Sleep Apnea That Determine Its High Prevalence in Resistant Hypertension. Yonsei Med J 2015; 56: 1258-65.

21. Marrone 0, Bonsignore MR. Blood-pressure variability in patients with obstructive sleep apnea: current perspectives. Nat Sci Sleep 2018; 10: 229-42. [CrossRef]

22. Garcia CE, Drager LF, Krieger EM, Negrão CE, Bortolotto LA, Lorenzi-Filho $\mathrm{G}$, et al. Arousals are frequent and associated with exacerbated blood pressure response in patients with primary hypertension. Am J Hypertens 2013; 26: 617-23. [CrossRef]

23. Peppard PE, Young T, Palta M, Skatrud J. Prospective study of the association between sleep-disordered breathing and hypertension. N Engl J Med 2000; 342: 1378-84. [CrossRef]

24. Cano-Pumarega I, Durán-Cantolla J, Aizpuru F, Miranda-Serrano E, Rubio R, Martínez-Null C, et al. Obstructive Sleep Apnea and Systemic Hypertension Longitudinal Study in the General Population: the Vitoria Sleep Cohort. Am J Resp Crit Care 2011; 184: 1299-304.

25. Wu H, Zhan X, Zhao M, Wei Y. Mean apnea-hypopnea duration (but not apnea-hypopnea index) is associated with worse hypertension in patients with obstructive sleep apnea. Medicine (Baltimore) 2016; 95: e5493. [CrossRef]

26. Haas DC, Foster GL, Nieto FJ, Redline S, Resnick HE, Robbins JA, et al. Age-dependent associations between sleep-disordered breathing and hypertension: importance of discriminating between sys- tolic/diastolic hypertension and isolated systolic hypertension in the Sleep Heart Health Study. Circulation 2005; 111: 614-21. [CrossRef]

27. Wang L, Cai A, Zhang J, Zhong Q, Wang R, Chen J, et al. Association of obstructive sleep apnea plus hypertension and prevalent cardiovascular diseases: A cross-sectional study. Medicine (Baltimore) 2016; 95: e4691. [CrossRef]

28. Cano-Pumarega I, Barbé F, Esteban A, Martínez-Alonso M, Egea C, Durán-Cantolla J; Spanish Sleep Network(*). Sleep Apnea and Hypertension Are There Sex Differences? The Vitoria Sleep Cohort. Chest 2017; 152: 742-50. [CrossRef]

29. Diogo LN, Pinto P, Bárbara C, Monteiro EC, Papoila AL. Neck circumference and body mass index as independent predictors of hypertension misclassification in patients suspected of having obstructive sleep apnea. Blood Press Monit 2015; 20: 8-15. [CrossRef]

30. Donadio V, Liguori R, Vetrugno R, Contin M, Elam M, Wallin BG, et al. Daytime sympathetic hyperactivity in OSAS is related to excessive daytime sleepiness. J Sleep Res 2007; 16: 327-32. [CrossRef]

31. Feng J, He QY, Zhang XL, Chen BY; Sleep Breath Disorder Group, Society of Respiratory Medicine. Epworth Sleepiness Scale may be an indicator for blood pressure profile and prevalence of coronary artery disease and cerebrovascular disease in patients with obstructive sleep apnea. Sleep Breath 2012; 16: 31-40. [CrossRef]

32. Goldstein IB, Ancoli-Israel S, Shapiro D. Relationship between daytime sleepiness and blood pressure in healthy older adults. Am J Hypertens 2004; 17: 787-92. [CrossRef]

33. Tam W, Ng SS, To KW, Ko FW, Hui DS. The interaction between hypertension and obstructive sleep apnea on subjective daytime sleepiness. J Clin Hypertens (Greenwich) 2019; 21: 390-6. [CrossRef]

34. Castro-Diehl C, Roux AVD, Redline S, Seeman T, McKinley P, Sloan $\mathrm{R}$, et al. Sleep Duration and Quality in Relation to Autonomic Nervous System Measures: The Multi-Ethnic Study of Atherosclerosis (MESA). Sleep 2016; 39: 1927-40. [CrossRef]

35. The National Institute for Health and Care Excellence (2019). Hypertension in adults: diagnosis and management (NICE Guideline 136) London 2019. Available at; URL; https://www.nice.org.uk/guidance/ng136 